\title{
Diabetic Ketoacidosis with Two Life Threatening Infections: Mucormycosis, and Bilateral Emphysematous Pyelonepritis, Preciptating Erythema Nodosum Leprosum as the Initial Presentation of Diabetes
}

\author{
Ahmed Daoud $^{1 *}$, Amira Elbendary ${ }^{2,3}$, Mohanad Elfishawi ${ }^{1}$, Mahmoud Rabea', Mostafa Alfishawy ${ }^{1,4}$, Sholkamy Amany MD and Wasfy Ayda MD \\ 1 Internal Medicine department - Kasr Alainy Hospital, Cairo University, Egypt \\ ${ }^{2}$ Dermatology Department, Kasr Alainy Hospital, Cairo University, Egypt \\ ${ }^{3}$ Ackerman Academy of Dermatopathology, New York, New York, USA \\ ${ }^{4}$ Ichan School of Medicine, Mount Sinai/ Queens General Hospital, New York, USA
}

\begin{abstract}
Emphysematous pyelonephritis is an acute necrotizing renal and perirenal infection, caused by gas forming organism. Mucormycosis is an opportunistic aggressive fungal infection causing tissue thrombosis and necrosis Erythema nodosum leprosum reaction is an inflammatory reaction occurring in borderline and lepromatous leprosy before, during or after multidrug treatment, where immune complexes deposit in various organs resulting in considerable damage to the organs that were site of deposition. Both emphysematous pyelonephritis and mucormycosis are infections that occur principally in diabetics, especially with poor control of blood sugar. Herein we report a 27 year old woman presenting to the emergency department with diabetic ketoacidosis as a first presentation of diabetes, where array of investigations revealed emphysematous pyelonephritis, palatal mucormycosis, and erythema nodosum leprosum. The early aggressive management with the correction of blood glucose and ketoacidosis help to give a successful outcome to the patient. To the best of our knowledge, this case is the first in English literature to report coexisting bilateral emphysematous pyelonephritis and palatal mucormycosis in a diabetic patient, precipitating erythema nodosum leprosum, and highlights the possibility of occurrence of more than one serious condition in a diabetic at a time.
\end{abstract}

Keywords: Diabetic ketoacidosis; Emphysematous pyelonephritis; Palatal mucormycosis; Erythema nodosum leprosum

\section{Introduction}

Diabetes mellitus has an increased susceptibility to infections, with some specific infections that are more common in diabetics and others which are nearly exclusive to them. The altered immunity in diabetics plays a major role for this susceptibility. There is reduced efficacy of leukocyte phagocytosis, chemotaxis and adherence, in addition to the depressed function of polymorphonuclear leukocyte especially in the presence of acidosis [1]. Antioxidant system may also be impaired leading to decreased bactericidal activity [2]. Infections which are reported to occur principally in diabetics include invasive otitis externa, the emphysematous infections including emphysematous cholecystitis, pyelonephritis and cystitis, and rhinocerebral mucormycosis [3]. Some of these infections have high mortality rate unless aggressive early management was taken. We present here a female patient with no previous medical history except for lepromatous leprosy presenting with diabetic ketoacidosis associated with bilateral emphysematous pyelonephritis, mucormycosis of the hard palate, which precipitate a type II lepra reaction.

\section{Case Presentation}

A 27 year-old female patient presented to the emergency department with a two week history of fever, exertional dyspnea and abdominal pain. The pain was diffuse dull aching associated with dysuria. Her past medical history included lepromatous leprosy from 3 years in which multidrug therapy was prescribed for one year.

On physical examination she was alert and oriented with core temperature of $38.5^{\circ} \mathrm{C}$, tachycardia at 120 /minute and rapid deep breathing at $30 /$ minute. She was pale with a tinge of jaundice. Oral examination revealed a black plaque measuring $3 \times 2 \mathrm{~cm}$ with mucosal denudation in the hard palate. Abdominal examination revealed bilateral tender renal angles. Skin examination revealed facial erythematous papulonodular lesions, and erythema in thenar and hypothenar eminences of both hands. On neurological examination, Glove \& Stock hyposthesia and thickened ulnar nerve was noted. Fundoscopy revealed non-proliferative diabetic retinopathy.

Laboratory investigations revealed hyperglycemia, blood glucose of $490 \mathrm{mg} / \mathrm{dl}$, urinalysis $2+$ for acetone, and high anion gap acidosis; ABG showed $\mathrm{pH}=7.29, P_{2} \mathrm{CO}_{2}=13 \mathrm{mmHg}, P \mathrm{O}_{2}=73 \mathrm{mmHg}, \mathrm{HCO}_{3}=6.3$ $\mathrm{mmol} / \mathrm{l}, \mathrm{O}_{2}$ Sat. $=92 \%$; and $\mathrm{CBC}$ showed leukocytosis with microcytic anemia and thrombocytopenia, WBCs $=12.5 \times 10^{3} / \mathrm{ml}, \mathrm{Hb}=7 \mathrm{~g} / \mathrm{dl}$, PLTs $=44 \times 10^{3} / \mathrm{ml}$, renal impairment was noted, serum urea $=215 \mathrm{mg} / \mathrm{dl}$, serum creatinine $=4.9 \mathrm{mg} / \mathrm{dl}, \mathrm{Na}=139 \mathrm{mEq} / \mathrm{l}, \mathrm{K}=3.9 \mathrm{mEq} / \mathrm{l}$, deranged hepatic functions, $A L T=57 \mathrm{U} / \mathrm{l}(\mathrm{N}=7-40), \mathrm{AST}=80 \mathrm{U} / \mathrm{l}(\mathrm{N}=7-38)$, Bil. $\mathrm{T}=2.97 \mathrm{mg} / \mathrm{dl}, \mathrm{Bil} . \mathrm{D}=2.59 \mathrm{mg} / \mathrm{dl}$., ESR=130 $1^{\text {st }}$ hour, $\mathrm{CRP}=389 \mathrm{mg} / \mathrm{l}$ $(<6), \mathrm{ANA}, \mathrm{ADNA}$ and hepatitis markers were negative.

The patient was admitted to the ICU with the diagnosis of Diabetic Ketoacidosis (DKA) with renal impairment and provisional diagnosis of mucormycosis. Treatment started in the form of Insulin infusion, IV fluids monitored by central venous pressure and urine output, cultures

*Corresponding author: Ahmed Daoud, MD, 2250 Holly Hall street, Apartment 126, Houston , Tx 77054, Tel: 8239297124; E-mail: ahmed.daoud84@yahoo.com Received June 19, 2014; Accepted September 16, 2014; Published September 24, 2014

Citation: Daoud A, Elbendary A, Elfishawi M, Rabea M, Alfishawy M, et al. (2014) Diabetic Ketoacidosis with Two Life Threatening Infections: Mucormycosis and Bilateral Emphysematous Pyelonepritis, Preciptating Erythema Nodosum Leprosum as the Initial Presentation of Diabetes. J Diabetes Metab 5: 433 doi:10.4172/2155-6156.1000433

Copyright: $\odot 2014$ Daoud A, et al. This is an open-access article distributed under the terms of the Creative Commons Attribution License, which permits unrestricted use, distribution, and reproduction in any medium, provided the original author and source are credited. 
Citation: Daoud A, Elbendary A, Elfishawi M, Rabea M, Alfishawy M, et al. (2014) Diabetic Ketoacidosis with Two Life Threatening Infections: Mucormycosis, and Bilateral Emphysematous Pyelonepritis, Preciptating Erythema Nodosum Leprosum as the Initial Presentation of Diabetes. J Diabetes Metab 5: 433 doi:10.4172/2155-6156.1000433

drawn and IV Ceftriaxone initiated. Urinalysis revealed pus cells over 100 , urine and blood cultures were negative.

Tissue biopsy taken from the black plaque in the hard palate revealed irregular non septate hyphea, some show irregular branching at a right angle (Figure 1). CT Para nasal sinuses revealed increased density of the soft tissue in maxillary and sphenoidal sinuses, but no destruction noted (Figure 2). Based on the clinical, histopathologic and radiologic findings mucormycosis was considered.

Type II lepra reaction was diagnosed based on the erythematous papulonodular lesions present on her face, history of lepromatous leprosy with manifestation of neuropathy, and histopathologic confirmation.

After two days there was no improvement regarding kidney functions, glycemic control, and the abdominal pain. Ultrasound showed high echogenic areas on both kidneys with dirty shadowing. C.T abdomen revealed enlarged both kidneys, with heterogeneous multiple areas of air density and perinephric fat stranding, a picture of bilateral emphysematous pyelonephritis (Figure 3a).

Urological consultation suggested changing antibiotics and continuing conservative management.

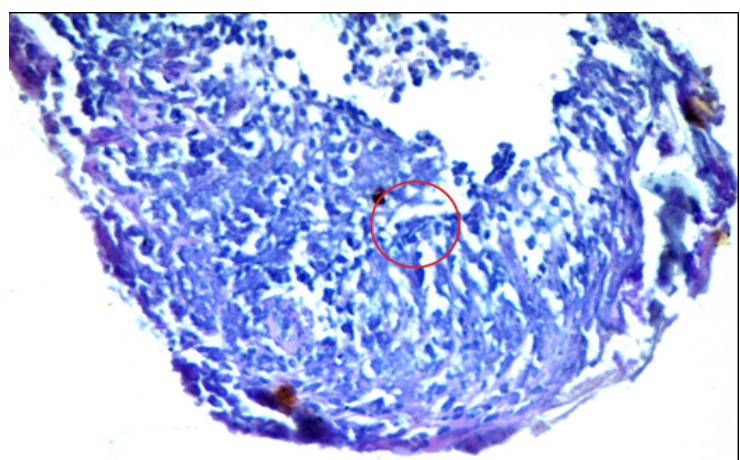

Figure 1: micrograph showing non-septate hyphae in necrotic tissue $(H$ \& $E$ stain, Original magnification $\times 400$ ).

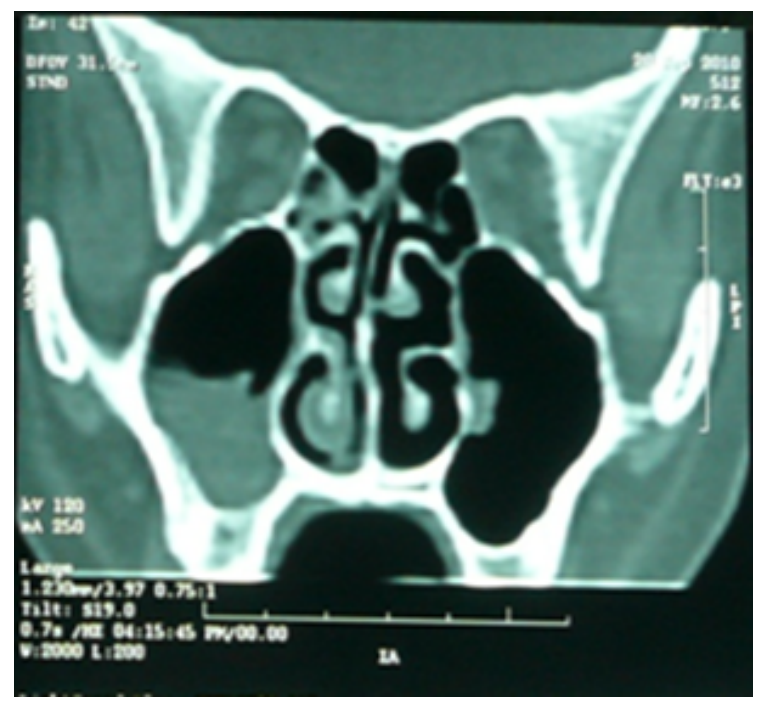

Figure 2: CT of the paranasal sinuses showing increased density of the soft tissue in maxillary and sphenoidal sinuses, no destruction noted in the bone.

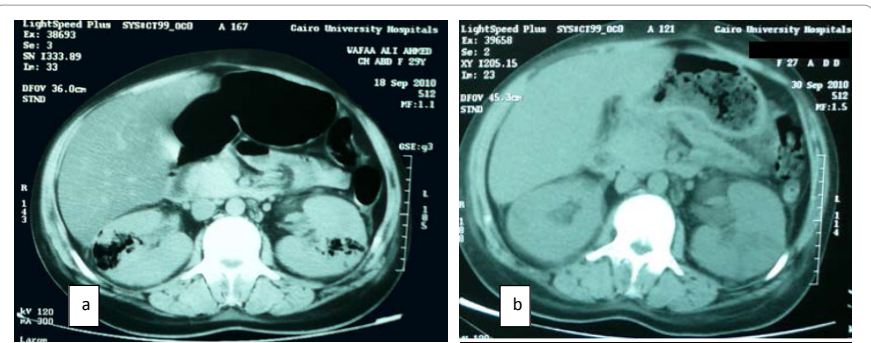

Figure 3: CT abdomen of the patient showing (a) Bilateral emphysematous pyelonephritis, with enlargement of both kidneys and heterogeneous multiple areas of air density and perinephric fat stranding (b) After treatment, the areas of heterogeneous air density resolved..

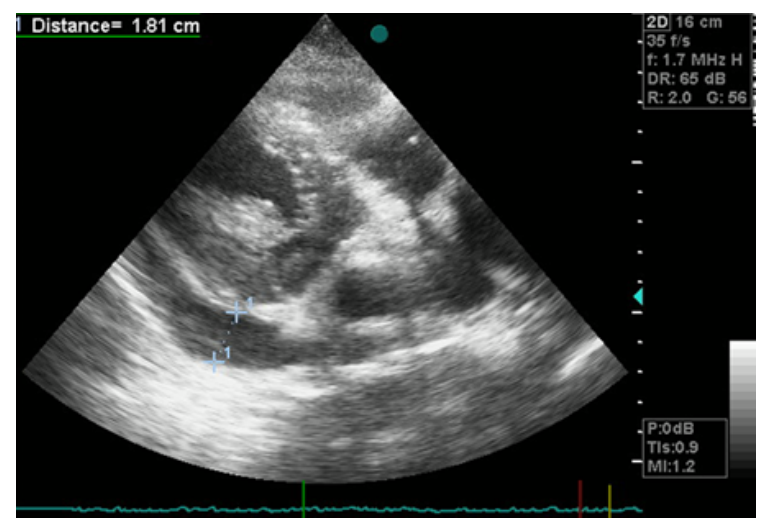

Figure 4: Echocardiography of the patient demonstrating posterior pericardial effusion.

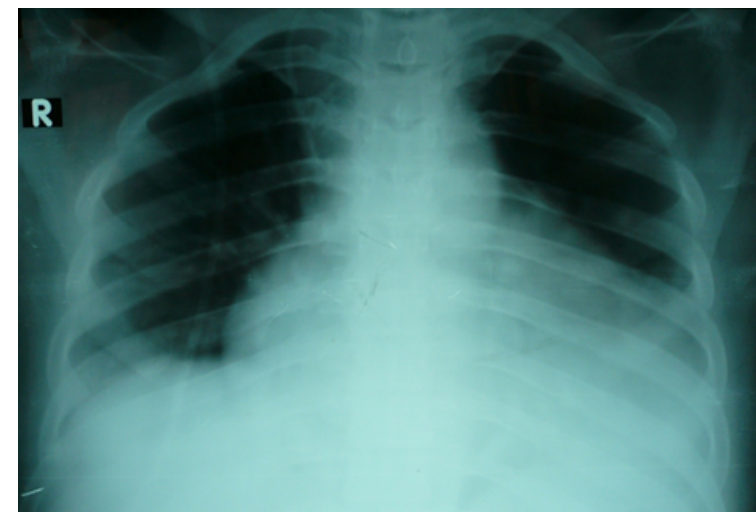

Figure 5: Chest Xray showing cardiomegaly and lung oligemia.

The patient received 5 sessions of haemodialysis, IV Ciprofloxacin and Metronidazole according to hospital antibiogram for emphysematous pyelonephritis. Amphotericin B was given as treatment of mucormycosis. Corticosteroids at a dose of $0.5 \mathrm{mg} / \mathrm{kg} / \mathrm{day}$ was given as a treatment of leprosy reaction.

An echocardiography was done revealing considerable posterior pericardial effusion (Figure 4).

Ten days later, the patient became hypoxic with hypotension and distant heart sounds, Jugular venous distention and Central Venous Pressure $(\mathrm{CVP})$ of $20 \mathrm{~cm}$ water. Chest $\mathrm{X}$ ray revealed new onset cadiomegaly, oligaemic lungs and right mild pleural effusion (Figure 5). Echocardiography revealed cardiac tamponade. 
Citation: Daoud A, Elbendary A, Elfishawi M, Rabea M, Alfishawy M, et al. (2014) Diabetic Ketoacidosis with Two Life Threatening Infections: Mucormycosis, and Bilateral Emphysematous Pyelonepritis, Preciptating Erythema Nodosum Leprosum as the Initial Presentation of Diabetes. J Diabetes Metab 5: 433 doi:10.4172/2155-6156.1000433

Urgent pericardiocentesis was done and $800 \mathrm{cc}$ of hemorrhagic effusion with debris were aspirated after which dyspnea was relieved, CVP dropped to $5 \mathrm{~cm}$ water and the blood pressure returned to normal. Pericardial fluid analysis was exudative type, its total proteins $=4.5$ (Serum total protiens $=6.6$ ) and $\mathrm{LDH}=1751$ (Serum $\mathrm{LDH}=715$ ). Culture of the effusion revealed no growth, adenosine deaminase (ADA) and PCR for $M$. tuberculosis DNA were negative, and cytology revealed no malignant cells.

The patient improved regarding glycemic control, renal impairment (creatinine decreased from 4.9 to 0.7 ) and emphysematous pyelonephritis (as documented by follow up CT abdomen two weeks later) (Figure 3b). Patient was later discharged after one month.

\section{Discussion}

In diabetics, the uncontrolled blood glucose, damaged tissue perfusion, and low immunity are factors helping the development of emphysematous pyelonephritis (EPN) [4,5]. EPN is an acute necrotizing parenchymal and peri-renal infection caused by gas forming uropathogens. The most common causative organisms include E.coli (66\%) and most of the other causative organisms are gram negative bacilli [6]. 90\% of Emphesematous pyelonephritis cases were in diabetic patients [7], where In non-diabetics, it may occur in patients with urinary obstruction, alcoholics, and immunocompromised patients [8].

EPN presents with fever (56\%), vomiting (16\%), abdominal pain (7\%), shock (16\%) and confusion (24\%) [9]. Other rare presentations reported are diabetic ketoacidosis, acute respiratory distress syndrome (ARDS), and Disseminated Intravascular Coagulopathy (DIC). 70-80\% of the patients show leucocytosis, and $15-20 \%$ show thrombocytopenia $[10,11]$. Acute renal failure, haematuria and proteinuria are positive findings in EPN [12].

Diagnosis is mainly radiological. The presence of gas within renal structures is diagnostic for EPN [13]. Plain abdominal radiograph and ultrasonography are only accurate in $65 \%$ and $69 \%$ of cases, respectively which made abdominal CT an essential tool for early diagnosis and management [14]. Based on CT findings, Haung and Tseng proposed a modified staging system, as four classes correlated with severity of the disease (Table 1) [12].

Treatment of EPN includes antibiotics according to the antibiogram, alone or combined with percutaneous drainage of the kidney guided with CT or US [14]. Nephrectomy is preserved for unresponsive cases especially in class III and IV [15]. Our case showed a good outcome following medical management only besides the correction of the acid base balance and glycemic control in spite of acute renal failure, and bilaterality of the disease which can lead to high mortality rate that was reported to reach $21 \%$ [15].

Interestingly our patient presented besides EPN and DKA by mucormycosis. Mucormycosis is an aggressive opportunistic fungal infection, caused by fungi of Mucorales group. It occurs primarily in poorly controlled diabetes mellitus, and in immunocompromised patients especially those with neutropenia and transplant recipients on corticosteroids [16]. Mucormycosis is classified into rhinocerebral, cutaneous, pulmonary, gastrointestinal and disseminated types based on the anatomic site of occurrence [17]. Oral involvement may occur due to disseminated infection usually through the nose or from direct wound contamination [18]. Vascular invasion by the hyphae leads to thrombosis and eventually infarction of the tissues and this is reflected clinically as an erythematous phase that could be associated with edema followed by violaceous color changes and eventually a black, necrotic lesions as a result of tissue necrosis [17]. The mean time reported for oral mucormycosis to develop is about 8 days and palatal ulcer develops at the $9^{\text {th }}$ to $10^{\text {th }}$ day [17], and this emphasize the importance of early diagnosis and treatment. In patients with DKA, release of iron ions from their attachment to serum proteins occur due the acidosis present, these ions are essential as they are incorporated into Mucorales energy metabolism, enabling them to invade the host's cells [19], besides the impaired function of neutrophils that is present in DKA make these patients highly vulnerable to be infected by Mucormycosis. These facts demonstrate the necessity of correction of the glucose level and ketoacidosis in conjunction with antifungal agents for therapeutic success.

Our patient was diagnosed with mucormycosis based on the clinical finding of a small black necrotic lesion in the hard palate in a decompensated diabetic patient confirmed by the presence of multiple irregular non-septate hyphae on histopathologic examination and showed favorable response to Amphtericin B besides the correction of the general condition. Delay in management of this patient with this maxillary affection could lead to a serious complication, namely cavernous sinus thrombosis [18]. Surgical debridement associated with systemic antifungal agents and correction of the underlying cause is reported to be the most effective way in treatment of palatal mucormycosis [20-22].

These infections in our patient precipitated type II lepra reaction, which is also known as Erythema Nodosum Leprosum (ENL). Our patient gave history of lepromatous leprosy three years ago that was treated for one year and follow up skin smear showed no bacilli.

ENL is an inflammatory reaction where immune complexes deposit in various tissues with varying presentation accordingly. It is proposed that it may be precipitated by stress, pregnancy, lactation, and intercurrent infection [23]. The reaction was reported to develop before, during or after treatment of the underlying leprosy. It is characterized by rapid appearance of painful, erythematous subcutaneous nodules that has predilection to the face, extensor surfaces of upper and lower limbs associated with fever, anorexia and malaise [24].

Neutrophil functions in leprotic patients remain intact, making them not susceptible to infection with Mucorales fungi. Very rare reports in the literature reported the occurrence of mucormycosis with leprosy that is complicated with ENL [25]. However the coexistence of both diseases could be a result of the immunosuppressive treatment given to control lepra reactions, or the presence of immunosuppressive condition such as diabetes mellitus.

\begin{tabular}{|l|l|l|}
\hline Classification & CT findings & Recommended management \\
\hline Class I & gas limited to the collecting system & medical management alone or medical management combined with percutaneous drainage \\
\hline Class II & gas limited to the renal parenchyma alone & \\
\hline Class IIIA & perinephric extension of gas or abscess & medical management plus percutaneous drainage, non-responders in this group required \\
\hline Class IIIB & Extension of gas beyond the Gerota fascia & nephrectomy \\
\hline Class IV & EPN in a solitary kidney or bilateral EPN & \\
\hline
\end{tabular}

Table 1: Classification of EPN according to CT findings with the recommended management for each. 
Citation: Daoud A, Elbendary A, Elfishawi M, Rabea M, Alfishawy M, et al. (2014) Diabetic Ketoacidosis with Two Life Threatening Infections: Mucormycosis, and Bilateral Emphysematous Pyelonepritis, Preciptating Erythema Nodosum Leprosum as the Initial Presentation of Diabetes. J Diabetes Metab 5: 433 doi:10.4172/2155-6156.1000433

Regarding the pericardial effusion and tamponade that developed in our patient, there was no definite reason for such complication. We assumed it might be a complication of severe sepsis. To the best of our knowledge, the association of exudative pericardial effusion and EPN is the first in English literature to be reported, but there was a case of ascending necrotizing mediastinitis without pericardial effusion reported as a complication of EPN [26].

\section{Conclusion}

Defects in the host defense mechanisms in diabetic patients make them vulnerable to opportunistic infections, we herein reported a case of newly discovered diabetes complicated by diabetic ketoacidosis, coexisting with two infections principally occurring in diabetics namely, mucormycosis and emphysematous pyelonephritis, that precipitate the occurrence of erythema nodosum leprosum. This case highlights the importance of the aggressive early management of infections side to side with the glycemic correction to make a successful outcome. To the best of our knowledge, this case is the first in English literature to report coexisting bilateral emphysematous pyelonephritis and palatal mucormycosis in diabetic patient, precipitating erythema nodosum leprosum, and emphasize the clinicians to be aware of the possibility of occurrence of more than one serious condition in a diabetic at a time.

\section{References}

1. Valerius NH, Eff C, Hansen NE, Karle H, Nerup J, et al. (1982) Neutrophil and lymphocyte function in patients with diabetes mellitus. Acta Med Scand 211: 463-467.

2. Muchová J, Liptáková A, Országhová Z, Garaiová I, Tison P, et al. (1999) Antioxidant systems in polymorphonuclear leucocytes of Type 2 diabetes mellitus. Diabet Med 16: 74-78.

3. Joshi N, Caputo GM, Weitekamp MR, Karchmer AW (1999) Infections in patients with diabetes mellitus. N Engl J Med 341: 1906-1912.

4. Flores G, Nellen H, Magaña F, Calleja J (2002) Acute bilateral emphysematous pyelonephritis successfully managed by medical therapy alone: a case report and review of the literature. BMC Nephrol 3: 4.

5. Asgari SA (2004) Successful medical treatment of emphysematous pyelonephritis. Urol J 1: 282-283.

6. Pinninti R, Pandichelvan R, Ameen KH (2012) Emphysematous pyelonephritis: Presenting as diabetic ketoacidosis. Indian J Endocrinol Metab 16 Suppl 1: S126-127.

7. Pagnoux C, Cazaala JB, Méjean A, Haas C, Brochen J, et al. (1997) [Emphysematous pyelonephritis in diabetics]. Rev Med Interne 18: 888-892.

8. Leons J, Humad SM, Sara YA (2004). Emphysematous pyelonephritis: Case report. Kuwait Med J 36:134-136.

9. Michaeli J, Mogle P, Perlberg S, Heiman S, Caine M (1984) Emphysematous pyelonephritis. J Urol 131: 203-208.

10. Tang HJ, Li CM, Yen MY, Chen YS, Wann SR, et al. (2001) Clinical characteristics of emphysematous pyelonephritis. J Microbiol Immunol Infect 34: 125-130.

11. Narlawar RS, Raut AA, Nagar A, Hira P, Hanchate V, et al. (2004) Imaging features and guided drainage in emphysematous pyelonephritis: a study of 11 cases. Clin Radiol 59: 192-197.

12. Huang JJ, Tseng CC (2000) Emphysematous pyelonephritis: clinicoradiological classification, management, prognosis, and pathogenesis. Arch Intern Med 160: 797-805.
13. McDermid KP, Watterson J, van Eeden SF (1999) Emphysematous pyelonephritis: case report and review of the literature. Diabetes Res Clin Pract 44: 71-75.

14. Somani BK, Nabi G, Thorpe P Hussey J, Cook J, N'Dow J et al. (2008) Is percutaneous drainage the new gold standard in the management of emphysematous pyelonephritis? Evidence from a systematic review. J Urol 179: 1844-1849.

15. Ubee SS, McGlynn L, Fordham M (2011) Emphysematous pyelonephritis. BJU Int 107: 1474-1478.

16. Erami M, Shams-Ghahfarokhi M, Jahanshiri Z, Sharif A, Razzaghi-Abyaneh M (2013) Rhinocerebral mucormycosis due to Rhizopus oryzae in a diabetic patient: a case report. J Mycol Med 23: 123-129.

17. Bonifaz A, Macias B, Paredes-Farrera F, Arias P, Ponce RM, et al. (2008) Palatal zygomycosis: experience of 21 cases. Oral Dis 14: 569-574.

18. Lador N, Polacheck I, Gural A, Sanatski E, Garfunkel A (2006) A trifungal infection of the mandible: case report and literature review. Oral Surg Oral Med Oral Pathol Oral Radiol Endod 101: 451-456.

19. Spellberg B, Edwards J Jr, Ibrahim A (2005) Novel perspectives on mucormycosis: pathophysiology, presentation, and management. Clin Microbiol Rev 18: 556-569.

20. Ruoppi P, Dietz A, Nikanne E, Seppa J, Markkanen H, et al. (2001) Paranasa sinus mucormycosis: a report of two cases. Acta Otolaryngol 121: 948-952.

21. Salisbury PL 3rd, Caloss R Jr, Cruz JM, Powell BL, Cole R, et al. (1997) Mucormycosis of the mandible after dental extractions in a patient with acute myelogenous leukemia. Oral Surg Oral Med Oral Pathol Oral Radiol Endod 83: 340-344

22. Vijayabala GS, Annigeri RG, Sudarshan R (2013) Mucormycosis in a diabetic ketoacidosis patient. Asian Pac J Trop Biomed 3: 830-833.

23. Sharma VK, Malhotra AK. Valia RG, Valia AR (2008). IADVL Textbook of dermatology. 3rd edn. Mumbai: Bhalani Publishing House. Leprosy: Classification and clinical aspects; pp. 2032-2069.

24. Kamath S, Vaccaro SA1, Rea TH1, Ochoa MT2 (2014) Recognizing and managing the immunologic reactions in leprosy. J Am Acad Dermatol 71: 795803.

25. Basílio FM, Hammerschmidt M, Mukai MM, Werner B, Pinheiro RL, et al. (2012) Mucormycosis and chromoblastomycosis occurring in a patient with leprosy type 2 reaction under prolonged corticosteroid and thalidomide therapy. An Bras Dermatol 87: 767-771.

26. Dajer-Fadel WL, Pichardo-González M, Estrada-Ramos S, Palafox D, NavarroReynoso FP, et al. (2014) Ascending necrotizing mediastinitis secondary to emphysematous pyelonephritis. Asian Cardiovasc Thorac Ann. 22: 869-871. 